\title{
Estimation of Sulphur Containing Amino Acids in Soybean Products in Nigeria
}

\author{
David Ebuka Elijah",", Nwobodo Amarachukwu Grace², Okafor Chinedu Arthur ${ }^{3}$ \\ ${ }^{1}$ Department of Chemistry, Biochemistry/Molecular Biology, Federal University Ndufu Alike, Nigeria \\ ${ }^{2}$ Department of Biochemistry, Renaissance University, Nigeria \\ ${ }^{3}$ Department of Microbiology, Renaissance University, Nigeria
}

Copyright $\mathrm{O} 2016$ by authors, all rights reserved. Authors agree that this article remains permanently open access under the terms of the Creative Commons Attribution License 4.0 International License

\begin{abstract}
Five different samples of soybean products (Raw Soybeans Seed (RSS), Local Soybean Powdered Milk (LSPM), Local Soybean Liquid Milk (LSLM), Vita-milk and Chi-soymilk) were used for the analysis of sulphur containing amino acids (methionine and cysteine) contents. Qualitative analysis using thin layer chromatography technique was carried out on the soybean products to detect the presence of sulphur containing amino acids while spectrophotometric method involving methionine and cysteine standards were used to quantitatively estimate the two amino acids in the soybean products. The RF values (Retardation Factor) of 0.70 and 0.90 for methionine and cysteine standards respectively were used as control values. The presence of methionine in these five soybean products was detected with RF values of $0.69,0.70,0.70,0.70$ and 0.71 for RSS, LSPM, LSLM, Vita-milk and Chi-soymilk, respectively. The presence of cysteine in these five samples of soybean products was detected with RF values $0.91,0.92$, $0.90,0.90$ and 0.92 for the five samples. The result of qualitative analysis confirms the presence of methionine and cysteine in all the samples. From the result of the spectrophometric analysis of the products, methionine concentration in $(\mathrm{g} / 100 \mathrm{ml})$ present in Vita-milk $(0.90 \pm 0.70)$ and Chi-soymilk $(0.64 \pm 0.02)$ is significantly higher $(\mathrm{p}<0.05)$ than in the control RSS $(0.47 \pm 0.02)$. Methionine concentration $(\mathrm{g} / 100 \mathrm{ml})$ present in Local Soybean Powdered Milk (LSPM), $(0.22 \pm 0.02)$ is significantly lower than RSS $(0.47 \pm 0.02)$ but not for Local Soybean Liquid Milk (LSLM) $(0.50 \pm 0.02)$. Cysteine concentration $(\mathrm{g} / 100 \mathrm{ml})$ present in Vita-milk (1.130 \pm 0.27$)$, Chi-soymilk $(0.590 \pm 0.06)$ and Local Soybean Liquid Milk $(0.610 \pm 0.03)$ is significantly higher $(\mathrm{p}<0.05)$ than the RSS control $(0.130 \pm 0.03)$. Also cysteine concentration $(\mathrm{g} / 100 \mathrm{ml})$ present in Local Soybean Powdered Milk $(0.126 \pm 0.02)$ is significantly lower $(p<0.05)$ than the RSS control $(0.130 \pm 0.03)$. An increase in both methionine and cysteine concentrations for Chi-soymilk and Vita-milk suggests that these soybean products were enriched with these amino acids during processing, hence can effectively replenish the lost sulphur amino acids in the
\end{abstract}

body due to the action of trypsin inhibitor present in soybeans.

Keywords Soybean Products, Amino Acids, Sulphur Amino Acids

\section{Introduction}

Soybean (Glycine Max), which belongs to the botanical family Leguminosae, is one of the important food resources that can combat diseases ascribed to mal- and under nutrition in developing countries [10]. On the other hand, raw soybean meals in the diet have been reported to cause growth retardation, impaired nutrient utilization, increased pancreatic secretion and pancreas enlargement in some monogastric animals and humans [4]. Serine proteinase inhibitors are considered to account for a significant part of these effects of raw soybeans [6]. Trypsin is one of the three principal digestive proteinases in the digestive tract of animals and humans [5]. In the digestive process, trypsin acts with the other proteinases to break down dietary protein molecules to their component peptides and amino acids. Kunitz Soybean Trypsin Inhibitor (KSTI) and Bowman-Birk Inhibitor (BBI) are the two major trypsin inhibitors in soybeans. These inhibitors are large, tightly folded proteins that are not completely deactivated during ordinary cooking [3]. Trypsin inhibitor present in soybean products inhibit the action of trypsin enzyme in the intestine leading to more synthesis of this enzyme and its subsequent loss from the body. Soybean processors have worked hard to get antinutrients (e.g. trypsin inhibitors) out of the finished product, particularly soybean protein isolate (SPI) which is the key ingredient in most soybean foods that imitate meat and dairy products, including baby formulas and some brands of soybean milk. Much of the trypsin inhibitor content can be removed through high-temperature processing, but not all. High temperature processing 
performed to inhibit or denature the inhibitor activity has unfortunate side-effect of denaturing the other proteins in soybean. [8]. Since sulphur containing amino acids (cysteine and methionine) are the major amino acids involved in the synthesis of trypsin in the body, standard soybean products are supposed to be enriched with these two amino acids. This will enable the body to replenish the lost sulphur containing amino acids as a result of the action of the trypsin inhibitor present in the soybean product. The main part of this study is devoted to the estimation of sulphur containing amino acids present in soybean products in Nigerian market. The results of this study will be used to ascertain the quality of the soybean products in the market and to which extent the standard production procedures are followed.

\section{Materials and Method}

\subsection{Materials}

Raw Soybean Seed (RSS), Local Soybean Powdered Milk (LSPM), Local Soybean Liquid milk (LSLM), Vita-milk, Chi-soymilk, were purchased directly from producers in Enugu State Nigeria.

\subsection{Chemicals and Reagents}

The following chemicals were obtained from Sigma Aldrich Chemical Company. Phenol, ninhydrin, cysteine amino acid, methionine amino acid, petroleum ether, sodium chloride, distilled water, sodium hydroxide, acetone, acetic acid, phosphoric acid, concentrated hydrochloric acid (Conc. $\mathrm{HCl}$ ) aluminium foil and $95 \%$ ethanol. All chemicals were of highest purity and of analytical grade.

\subsection{Equipment}

Ultraviolet spectrophotometer (CE Voltage 220Volts, frequency 50Hetz, power 40W, Model NO 722510154, B. Bran scientific instrument and scientific company England), water bath (model DK-420 power 220Volts50Hetz).

\section{Methods}

\subsection{Thin-layer Chromatography Analysis}

This method was used to detect the presence of the sulphur containing amino acids in the soybean products. Standard method for Thin-layer chromatographic procedure was used [9]. Briefly, the starting line, approximately $1 \mathrm{~cm}$ from the edge of the Thin-layer chromatographic paper was marked. The spots of individual amino acids and sample solutions were applied to the paper using a dry glass capillary. A mixture of n-butanol, acetic acid distilled water in volume ratio 5:1:5 were stirred for 10 minutes and allowed to separate into layers. The upper layer was used as the solvent. The paper was inserted into the eluent chamber, the solvent front allowed to travel up the plate until 7-10 $\mathrm{mm}$ from the lid. The solvent front was marked with pencil, the paper dried in the oven and sprayed with ninhydrin solution to identify the solutes. The retardation factor (Rf) values for each of the solutes present in each soybean sample were measured using the formula below. The $\mathrm{Rf}$ values of methionine and cysteine were used as reference or control to detect their presence in each of the test sample. See Table 1 and 2.

$R F=\frac{S F}{S f}$, Where $S F$ is the distance travelled by the solute (solute front), $s f$ is the distance travelled by the solvent (solvent front).

\subsection{Sample Hydrolysis}

The method used by Aishah Bujang \& Nurul Akmal Taib [1] was adopted for sample hydrolysis. $5 \mathrm{ml}$ of the soy sample was pipetted into a beaker and $0.5 \mathrm{ml}$ of the acid ninhydrin was added. The mixture was capped with an aluminum foil, heated in a water bath for $10 \mathrm{~min}$ at a temperature of $37^{\circ} \mathrm{C}$ and cooled in a tap water for $5 \mathrm{~min} .5 \mathrm{ml}$ of $95 \%$ ethanol was added into the mixture. A reagent blank was also prepared at the same condition.

\subsection{Quantification of Cysteine and Methionine by Spectrophotometric Method}

Cystein and Methionine concentrations were determined by methods of Gaitonde [11] and Ferrel [12] respectively. An acid ninhydrin reacts with the samples to form a pink product upon hydrolysis, with maximum absorption at $560 \mathrm{~nm}$ with cystein and $510 \mathrm{~nm}$ with methionine. The amount of cystein and methionine present in the soy samples were calculated by reference to a calibration curve (figure 1 and 2) obtained under similar conditions for known amounts of cysteine and methionine.

\subsection{Statistical Analysis}

The data were analyzed using the student's $t$ test. The results were expressed as mean \pm SEM at $95 \%$ confidence level. The significant level was taken at $(\mathrm{p}<0.05)$.

\section{Results}

Table 1. Retardation factor (Rf) values for methionine amino acid

\begin{tabular}{|c|c|}
\hline Soybean products & Retardation factor (Rf) \\
\hline Methionine (control) & 0.70 \\
\hline Raw Soybean Seed & $0.29,0.51,0.59,0.69,0.32$ \\
\hline Local Soybean Powdered Milk & $0.32,0.35,0.70,0.84,0.80,0.98$ \\
\hline Local Soybean Liquid Milk & $0.70,0.95$ \\
\hline Vita-milk & $0.46 .0 .69,0.70,0.89$ \\
\hline Chi-soymilk & $0.65,0.71,0.91$ \\
\hline
\end{tabular}


From Table 1.0 above, the presence of methionine amino acid was detected in all the soybean products. An Rf value of 0.70 for methionine was used as control. The five soybean products have $\mathrm{Rf}$ values close to the control value $0.69,0.70$, $0.70,0.70,0.71$, respectively for Raw Soybean Seed, Local Soybean Powdered Milk, Local Soybean Liquid Milk, Vita-milk and, Chi-soymilk.

Table 2. Retardation factor (Rf) values for cysteine amino acid

\begin{tabular}{|c|c|}
\hline Soybean products & Retardation factor (Rf) values \\
\hline Cysteine (control) & 0.90 \\
\hline Raw Soybean Seed & $0.91,0.51$ \\
\hline Local Soybean Powdered Milk & $0.24,0.43,0.92$ \\
\hline Local Soybean Liquid Milk & $0.26,0.66,0.72,0.80,0.90,0.94$ \\
\hline Vita-milk & $0.45,0.63,0.72,0.90$ \\
\hline Chi-soymilk & $0.11,0.211,0.611,0.75,0.92$ \\
\hline
\end{tabular}

From Table 2 above, the presence of cysteine amino acid was detected in all the soybean products. Rf values for 0.90 for cysteine was used as control. The five soybean products have $\mathrm{Rf}$ values close to the control value $0.91,0.92,0.90$, $0.90,0.92$, respectively for Raw Soybean Seed, Local Soybean Powdered Milk, Local Soybean Liquid Milk, Vita-milk and Chi-soymilk.

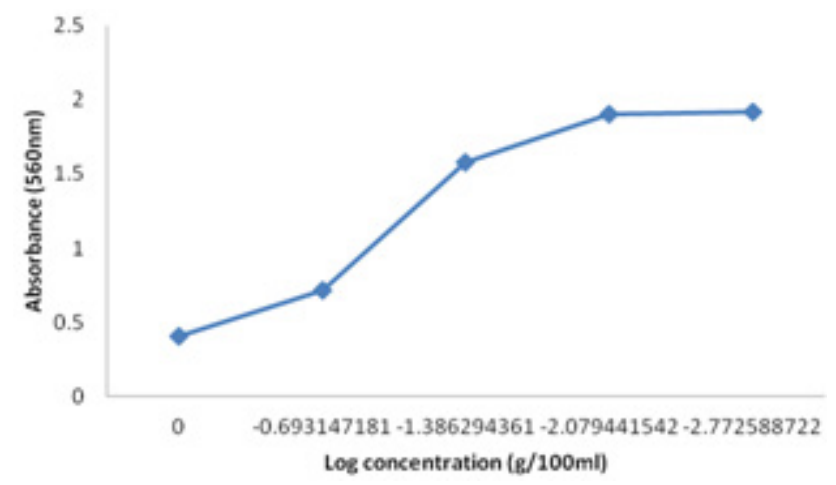

Figure 1. Graph of Absorbance against Methionine concentration

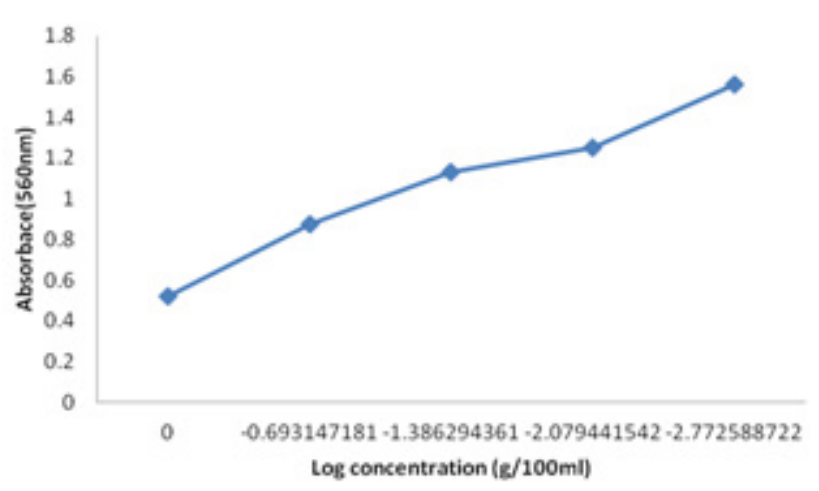

Figure 2. Graph of Absorbance against Cystein concentration

Figure 1 and 2 above show the calibration curves of both methionine and cystein standards. The concentrations of both amino acids in the soybean products were read from the graph.
Table 3. Concentrations of cysteine in soybean products

\begin{tabular}{|c|c|}
\hline Soybean products & Cysteine concentrations $(\mathrm{g} / 100 \mathrm{ml})$ \\
\hline Raw Soybean Seed( control) & $0.13 \pm 0.03$ \\
\hline Local Soybean Milk Powdered & $0.13^{\mathrm{b}} \pm 0.02$ \\
\hline Local Soybean Liquid Milk & $0.61^{\mathrm{a}} \pm 0.03$ \\
\hline Vita-milk & $1.13^{\mathrm{a}} \pm 0.27$ \\
\hline Chi-soymilk & $0.59^{\mathrm{a}} \pm 0.06$ \\
\hline
\end{tabular}

Result $=$ mean \pm SEM ${ }^{\text {a }}$ significantly higher compared to control. ${ }^{\mathrm{b}}$ significantly lower than control.

As shown in table 3 above cysteine concentration $(\mathrm{g} / 100$ $\mathrm{ml})$ present in Vita-milk (1.13 \pm 0.27) Chi-soymilk $(0.59 \pm 0.06)$ and Local Soybean Liquid Milk $(0.61 \pm 0.03)$ is significantly higher $(\mathrm{p}<0.05)$ than the one of Raw Soybean Seed that was used as control $(0.13 \pm 0.03)$. Also, cysteine concentration $(\mathrm{g} / 100 \mathrm{ml})$ present in Local Soybean Powdered Milk $(0.13 \pm 0.02)$ is significantly lower $(\mathrm{p}<0.05)$ than that of the Raw Soybean Seed control $(0.13$ $\pm 0.03)$.

Table 4. Concentration of methionine in soybean product

\begin{tabular}{|c|c|}
\hline Soybean products & Methionine concentration $(\mathrm{g} / 100 \mathrm{ml})$ \\
\hline Raw Soybean Seed (control) & $0.47 \pm 0.02$ \\
\hline Local Soybean Powdered Milk & $0.22^{\mathrm{b}} \pm 0.02$ \\
\hline Local Soybean Liquid Milk & $0.50^{\mathrm{c}} \pm 0.02$ \\
\hline Vita-milk & $0.90^{\mathrm{a}} \pm 0.07$ \\
\hline Chi-soymilk & $0.64^{\mathrm{a}} \pm 0.02$ \\
\hline
\end{tabular}

Result $=$ mean \pm SEM ${ }^{\mathrm{a}}$ significantly higher compared to control. significantly lower than control. 'No significant difference compared to control.

As shown in Table 4 above, methionine concentration in $(\mathrm{g} / 100 \mathrm{ml})$ present in Vita-milk $(0.90 \pm 0.07)$ and Chi-soymilk $(0.06 \pm 0.01)$ is significantly higher $(p<0.05)$ than the raw soybean seed $(0.47 \pm 0.02)$. Also methionine concentration $(\mathrm{g} / 100 \mathrm{ml})$ present in Local Soybean Powdered Milk $(0.22 \pm 0.02)$ is significantly lower than the raw soybean seed $(0.47 \pm 0.02)$.The Local Soybean Liquid Milk $(0.50 \pm 0.02)$ shows no significant difference in methionine concentration compared to that of the Raw Soybean Seed $(0.47 \pm 0.02)$.

\section{Discussion}

The presence of methionine and cystein as detected in the soybean products indicate their essential nature in proteins and enzymes synthesis. The lowest concentrations of methionine and cystein amino acids recorded in Raw Soybean Seeds agrees with Randy [7] according to which soybean seeds are almost deficient in sulphur containing amino acids, hence a standard soybean product should contain the sulphur containing amino acids which are cysteine and methionine to replenish these deficiencies [2]. This is because these are the major amino acids that are used to synthesize trypsin enzymes in the body and helps to replenish the lost sulphur amino acids in the body due to the 
action of trypsin inhibitors present in soybean product [3]. Chi-soymilk and Vita-milk contain higher sulphur amino acids (cysteine and methionine) when compared to the raw soybean control as seen in Table 3 and 4. This could be because they were enriched with these amino acids during production process. The Local Soybean Powdered Milk contains lower concentrations of these two amino acids. This could be as a result of the intensive dry heating involved during production. In Local Soybean Liquid Milk, methionine concentration remained unchanged while cysteine concentration showed a significant increase compared to control. The reason for these might be related to certain additives normally added to flavor the milk.

\section{Conclusions}

The presence of sulphur containing amino acids above control concentrations in Chi-soymilk and Vita-milk suggest that both soybean products have adequate nutritional values which may reduce the anti-nutritional effects of trypsin inhibitors in soybeans. Hence, the consumption of these soybean products poses no health challenge. The consumption of the locally produced soybean products should be done with care as they are not fortified with these amino acids which could result to continuous loss of trypsin enzymes involved in protein digestion. Further investigations on the Local Soybean Liquid Milk are needed decipher the reason for varying changes in the concentrations of the amino acids.

\section{REFERENCES}

[1] Aishah Bujang \& Nurul Akmal Taib (2014). Changes on amino acids content in soybean, garbanzo bean and groundnut during pre-treatments and tempe making. Sains Malaysiana, 43(4): 551-557

[2] Birk, Y (1996). Method of enzymology: Proteinase inhibitors from soybean. Journal of Biochemistry, 45: 695-739.
[3] Duranti M., Baribol A., Scarafoni A., Tedeschi G and Morazzani. P (2003). One step purification of Kunitz soybean trypsin inhibitor. Protein experiment and purification, 30:167-70.

[4] Jong Tseng Yen., Aldon H. Jensen and Joseph Simon (1977). Effect of dietary raw soybean and soybean trypsin inhibitors on trypsin and chymotrypsin activities in the pancreas and the small intestinal juice of growing swine. The Journal of Nutrition, 107: 156-165.

[5] Macedo. M. L., Garcia, V.A., Freire, M. G., and Richardson, M. (2007). Characteristics of kunitz trypsin inhibitor from raw soybean seeds. Phytochemistry, 68: 1104- 1111.

[6] Miroljob B. Barać., Slađana P. Stanojević., Snežana T. Jovanović and Mirjana B. Pešić (2004). Soy protein modification - a review. APTEFF (Acta Periodica Technologica), 35: 1-280

[7] Randy D. Dinkins ., M. S. Srinivasa Reddy., Curtis A. Meurer., Bo Yan1 Harold Trick., Francë Oise Thibaud-Nissen., John J. Finer., Wayne A. Parrott and Glenn B. Collins (2001). Increased sulfur amino acids in soybean plants over-expressing the maize $15 \mathrm{kda}$ zein protein. In Vitro Cell. Development Biological Plant, 37: 742-747.

[8] Richard J. Faris, Hui Wang, and Tong Wang (2008). Improving Digestibility of Soy Flour by Reducing Disulfide Bonds with Thioredoxin. Journal of Agricultural and Food Chemistry, 56: 7146-7150.

[9] Tin mar Lynn, Kyaw Nyein Aye and Khin Mar Khaing (2013). Study on the production of fermented soybean sauce by using Aspergillus oryzae and Apergillus flavus. Journal of Scientific and Innovative Research, Vol 2 Issue 2.

[10] Veronica Obatolu (2006). Impact of Soybean Utilization Project on Nutritional Status of under Five Children. Pakistan Journal of Nutrition, 5 (4): 348-354.

[11] Gaitonde M. K (1967). A spectrophotometric method for the direct determination of cystein in the presence of other naturally occurring amino acids. Biochemistry Journal, 104 (2): $627-33$.

[12] Ferrel R. E., Feller D. A. and Shepherd A.D (1969). Determination of free lysine and methionine in amino acid-fortified wheat. Paper presented at the AOCS-AACC joint meeting at Washington DC. 